\title{
Literature Review on the Influence of Two-Pillar Policy on Risk-Taking of Commercial Banks
}

\author{
Ming Zhang1 , Xinghua Liu², Yi Liu ${ }^{3}$ \\ ${ }^{1}$ Jiangxi University of Finance and Economics, Nanchang, China \\ ${ }^{2}$ School of Finance, Jiangxi University of Finance and Economics, Nanchang, China \\ ${ }^{3}$ Jiangxi College of Foreign Studies, Nanchang, China \\ Email: towmal@126.com,1xh7572@126.com
}

How to cite this paper: Zhang, M., Liu, X.H. and Liu, Y. (2019) Literature Review on the Influence of Two-Pillar Policy on Risk-Taking of Commercial Banks. Theoretical Economics Letters, 9, 2667-2677. https://doi.org/10.4236/tel.2019.97167

Received: September 16, 2019

Accepted: October 21, 2019

Published: October 24, 2019

Copyright ( 2019 by author(s) and Scientific Research Publishing Inc. This work is licensed under the Creative Commons Attribution International License (CC BY 4.0).

http://creativecommons.org/licenses/by/4.0/

\section{cc) (i) Open Access}

\begin{abstract}
This paper analyzes the impact of monetary policy and macro-prudential policy on the risk-taking of commercial banks, comments on the existing research results and existing problems, and looks forward to the future research direction. The article finds that the existing research is more comprehensive in the impact of monetary policy on the risk-taking of commercial banks, and has important theoretical value and practical significance. At the same time, there are still some shortcomings in the existing research, such as the research of macro-prudential policy on the risk-taking of commercial banks and the lack of synergy between the two-pillar policy in risk-taking and so on. Therefore, the follow-up research can be further carried out from the above two aspects.
\end{abstract}

\section{Keywords}

Two-Pillar Policy, Monetary Policy, Macro-Prudential Policy, Risk-Taking of Commercial Banks

\section{Introduction}

In the early stage of the financial crisis in 2007, in the important issue of maintaining the stability of the financial system, the position, role and role of the banking system are often underestimated [1]. It was not until the arrival of the subprime crisis in the United States that it was attacked by the traditional wrong view. As we all know, a huge financial system is often composed of many micro-individuals. Because these micro individuals have a high degree of correlation and influence on each other, when individual institutions have problems 
and expose risks, they are likely to form chain reactions, spread fermentation rapidly, and accumulate minor diseases, resulting in harm to the entire financial system. Bring serious harm to economic growth. The background of the outbreak of the subprime mortgage crisis in the United States is that the long-term loose monetary policy has given rise to huge asset price bubbles, accumulated the share of bank risk business, and the risks of bank financial institutions have superimposed on each other, magnified each other, and transmitted step by step. And eventually spread into a global financial crisis. With the high attention of governments and scholars, in the macro-prudential supervision and prevention, the risk-taking control of commercial banks is becoming more and more important and put on the important agenda [2].

Commercial banks make profits through risk. The formulation and change of monetary policy and macro-prudential policy will have an important impact on bank risk-taking, and the adjustment of two-pillar policy will also change the risk-taking of commercial banks [3]. This paper mainly summarizes four aspects: firstly, it analyzes the relationship between monetary policy and bank risk-taking; secondly, a summary of the relationship between macro-prudential policy and risk-taking of commercial banks includes the necessity of macro-prudential supervision, its objectives and tools, the relationship between policy and risk-taking, and the summary of empirical research [4]. This part of the research is less in China, which provides more research space for this paper. Thirdly, the coordination of macro-prudential policy and monetary policy, as well as the relationship between two-pillar policy and risk-taking of commercial banks, the current research on two-pillar policy and risk-taking is relatively few, which also provides space for this paper [5]. Finally, in the aspect of literature review, the main content is the review of the above existing research, and obtains the research space of this paper in three aspects: monetary policy, macro-prudential policy, and the impact of two-pillar policy coordination on the risk-taking of commercial banks [6].

\section{Monetary Policy and Risk-Taking}

To some extent, the subprime crisis is not only a global financial tsunami, but also a vivid and profound risk warning lesson. People gradually realize that one of the most direct influencing factors of macro systemic risk is the risk preference of commercial banks from generation to amplification, from accumulation to outbreak. In the research on the transmission channel of monetary policy, whether it is the monetary channel or the credit channel, it is considered that commercial banks are passive rather than active in the face of risk, ignoring the behavior of commercial banks to actively participate in and create risk [7]. From the present point of view, this view is obviously one-sided, the profit-seeking nature of commercial banks makes them have the inherent driving force to take risks in pursuit of higher returns, especially in the context of loose monetary policy [8]. This internal driving force is even stronger [9]. 
Based on the present, looking back on the past, it is not difficult to find that the core reason for the outbreak of the subprime mortgage crisis is that financial institutions, represented by banks, face the double temptation of low interest rate environment and high profit return, driven by the profit-seeking nature of their capital. Their own subjective willingness to take risks continues to strengthen, lending a large amount of capital to low-qualified customers, and housing prices and the prices of real estate-based credit and its asset securitization derivatives rise, resulting in a bubble and eventually burst [10].

Based on this, it is Borio and Zhu that put forward the concept of "risk-taking channel" (risk-taking channel) for the first time. They clearly pointed out the scope of the impact of loose monetary policy on commercial banks, including not only the scale of credit, but also risk appetite. Under the stimulus of loose monetary policy, commercial banks have a strong willingness to receive external funds, and under this trend, commercial banks may lower their credit audit in order to increase the overall operating risk. Even the accumulation of systemic risk in the banking sector as a whole [11].

In the study of Borio and Zhu (2008), it further expounds three ways in which monetary policy affects the risk-taking behavior of commercial banks. The emergence of the three ways is mainly based on three kinds of effects.

The first approach is based on the "valuation effect", banks according to the valuation of the capital demand side and make the corresponding risk-taking behavior. For companies that need capital, their value, income and cash flow are affected by interest rates, which in turn have an impact on the risk appetite of bank loans. Low interest rates can increase the valuation of a company's assets, which in turn increases the willingness of banks to take risks.

The second approach is based on the "yield-chasing effect", where banks and other financial institutions have specific requirements for yields. Banks can only make the risk preference more radical, increase the allocation of high-risk assets, in order to improve their own returns and achieve the target rate of return.

The third approach is based on the "communication and exchange effect with the central bank", that is, commercial banks analyze the adjustment strategy and change the risk preference from the central bank's statement and commitment to monetary policy. As the formulation department of monetary policy, the central bank's position statement and information disclosure on monetary policy in the future is of standard significance to the risk preference of commercial banks. The loose monetary policy of the central bank can provide a sufficient source of confidence for commercial banks. Commercial banks, with their profound expertise and rich experience, believe that under such circumstances, their own interests are expected to come to the bottom of the policy. In order to reduce the fear of risk-taking.

The proposal of the above theory has aroused widespread concern in the academic circles, and the research focus of the academic circles is mainly on the two levels of verifying the true and false and quantifying the influence, that is, judging whether it exists or not and the degree of influence. 
On the issue of verifying the true and false, a large number of studies support the conclusion that the conclusion is true, and the researchers have found the corresponding evidence from the credit data of different periods and different countries used data from Spain for 1984-2006 and Bolivia for 1999-2003. It is proved that the pursuit return effect and valuation effect in the risk-taking theory of commercial banks exist significantly, and commercial banks will indeed lower the loan standards and bear more risks in the environment of low interest rate.

In the research on the degree of influence, a large number of studies also provide positive support for this conclusion respectively, verifying that there is a positive correlation between the longer-term low interest rate monetary policy and the risk-taking willingness of commercial banks. And this kind of connection is stable, even when introducing different risk measurement variables, which verifies that the "communication and communication effect with the central bank" does exist.

At the same time, the domestic academic circles have made important progress in citing the economic data of the world and China [12].

In the face of higher capital adequacy ratio and operating scale, the willingness of commercial banks to bear risks will be reduced accordingly. Taking the expected default rate as the risk measurement index, studied the listed commercial banks and tested the risk-taking behavior of the major commercial banks in China. The research conclusions support the existence of risk-taking channels for commercial banks. With the deepening of the research, Wang Jinbin and Li Bo (2017) further found that the risk-taking behavior of commercial banks will be affected by different monetary policy tools, that is, the promotion of monetary easing and the restraint of monetary tightening. Under the control of quantitative monetary instruments, the former is weaker than the latter, and under the regulation of price monetary instruments, the former is stronger than the latter.

\section{Macro-Prudential Policy and Risk-Taking of Commercial Banks}

Although there is a general consensus in academic circles that macro-prudential supervision has an important impact on bank risk-taking, there are still great differences on the specific mechanism and the direction of influence. (Jacques and Nigro (1997) in order to further refine and quantify macro-prudential supervision, it takes regulators as the active subject, banks as the passive object, and macro-prudential supervision as the way of pressure. An important indicator parameter, "capital supervision pressure", is created as the pressure feeling value of banks in the face of macro-prudential supervision. The pressure of capital supervision is more macro-stage stress test from the perspective of supervision.

In view of the fact that the capital adequacy requirements of the minimum regulatory capital standards for banks and financial institutions in Basel I, II and 
III are all $8 \%$, so in the capital regulatory stress test, that is, $8 \%$ as the demarcation point. If the capital adequacy ratio meets the macro capital regulatory requirements, they all think that there is no regulatory pressure; on the contrary, if the capital adequacy ratio does not meet the macro capital regulatory requirements, the specific difference is treated as evidence to distinguish the macroprudential regulatory pressure.

Combined with a series of changes in the framework of policy makers from micro-prudential supervision to systematic supervision and macro-prudential supervision after the financial crisis, using the panel regression method, this paper puts forward a macro-prudential policy to monitor the soundness of the banking system in the European Union [13]. He assessed the impact of the macroeconomic environment on two key financial health indicators in the banking systems of 27 countries and developed a macro-prudential regulatory framework from a posteriori and forward-looking perspective.

A large number of conclusions drawn from the empirical analysis of the EU banking system have made the correlation between economic trends and bank economic health indicators clearer. There is a growing recognition that there must be greater co-ordination and cooperation between the authorities responsible for financial supervision and the government departments responsible for economic and fiscal policy, rather than going their own way, otherwise, it will eventually lead to systemic risks thus affecting financial stability. The research of scholars is a process of continuous deepening and continuous improvement, and there are different ways to prevent and solve the financial crisis, which reveals the process of this change in a large number of literatures.

While macroprudential policies aimed at mitigating systemic financial risks have become an integral part of the policy toolkits of many emerging markets and some advanced countries, however, its actual effect in economic activities has not been fully understood. With the help of panel data regression method, the author studies the balance sheet changes of nearly 2800 banks in 48 countries from 2000 to 2010 under different macro-prudential policies. Because of the prior nature of macroprudential tools, those considerations for controlling endogenous risks, such as restrictions on borrowers, will significantly reduce leverage than implementing counter-cyclical buffers.

The above situation extends to the field of commercial bank supervision, resulting in two major theories, namely, risk subsidy hypothesis and capital supervision hypothesis. The difference between the two views is mainly based on the relationship between capital and risk.

One is the risk subsidy hypothesis. In this hypothesis, it is considered that there is a negative correlation between capital and risk, and banks are willing to use deposit protection mechanism to seek asylum. Banks, as an important part of the national economy, with the financial support and credit endorsement of the government authorities, the probability of bank failure is very small, even in the most extreme cases, the government will support the banks [14] to ensure the overall security of the country's financial system. In short, banks will tend to 
choose high-risk-taking relative to smaller costs, which will further increase portfolio risk and reduce the level of capital. In the actual case study, the researchers found the empirical evidence of the risk subsidy hypothesis. Agusman, Monroe \& Gasbarro (2008) studied the situation of 46 Asian listed banks over a period of 15 years from 1998 to 2003. The results showed that there was no significant negative correlation between leverage ratio (equity-to-total assets) and risk., there is a significant negative correlation. The above research shows that for commercial banks with high risk, the risk-taking of high risk brings the corresponding leverage ratio. In other words, high-risk commitments need to be subsidized in order to be implemented based on a sample of 15 European banks from 1992 to 2000, concluded that less efficient banks tended to hold more capital and less risk. The study showed that for different commercial banks, Its risk-taking in different commercial bank size, capital level will be different. In the research of banking in China, there is also a negative correlation between supporting capital adequacy ratio and bank risk [15]. Thus it can be seen that the risk subsidy hypothesis is in line with the reality, and there is a negative correlation between bank capital and risk.

The second is the hypothesis of capital supervision. Capital regulation hypothesis holds that there is a positive correlation between capital and risk, and banks, encouraged by regulators, will increase capital and risk at the same time. With the strengthening of bank risk-taking behavior, its own costs in trading, operation, agency, supervision and other aspects will also rise, the less the capital of banks, the more so. From this point of view, banks with less capital will naturally adopt strategies to reduce risk behavior in order to reduce costs and save expenses. This is the logical deduction that there is a positive correlation between capital and risk level. In some empirical studies, this argument has been strongly supported. These empirical studies involve a wide range of regions, both Europe and the United States, but also China, at the same time, the time span involved is also very long, from the 1970s to recent years. As early as the early 1970s, Pettway (1976) proved that this positive correlation does exist in the US banking industry. Also, take the American banking industry as the sample, the research shows that there is a positive correlation between capital and profit (ROA), risk. In European countries, studied Swiss banks in different periods and came to the same positive conclusion as their American counterparts. When scholars focus on a wider range of areas, based on a sample of 181 large banks in 15 European countries, it more strongly supports the positive correlation point of view. This situation also exists in China through the data tracking of more than 70 commercial banks in China from 2003 to 2010, found that this positive correlation is also applicable in the Chinese banking industry [16].

Throughout the development of the world banking industry from the 1970s to the present, looking at countries all over the world, the commercial risk friction of banks and the financial instability caused by them are universal and inevitable in all kinds of circumstances. The reason is mainly based on two aspects: on the one hand, price stability can not ensure financial stability, on the other hand, in- 
dividual soundness can not guarantee the soundness of the system. In short, the reason can be understood from the concept of necessary and inadequate conditions. Price stability is a necessary and insufficient condition for financial stability, and individual soundness is also a necessary and insufficient condition for system soundness. This has broken the traditional view of economic theory in the past. First of all, let's explore the relationship between price stability and financial stability. In the past, it was generally believed that if finance was stable, then prices would naturally be stable, but with the renewal of development practice, this conclusion has been broken by the emergence of a large number of "paradoxes of financial instability" in the middle and late last century. Furthermore, the relationship between individual soundness and systematic soundness has been mentioned in the previous discussion on micro-prudential supervision and macroprudential supervision, which has been eloquently proved by the realistic cases in the past half century. In particular, the large-scale outbreak of the international financial crisis has forced people to re-attach importance to macro-prudential policies, which has triggered a new round of financial supervision system reform in developed countries in Europe and the United States.

It must be acknowledged that although the current research on macro-prudential policy has made a lot of progress and bright spots, it is still in the preliminary stage of policy research, and there are many problems that need to be paid attention to and solved. In the current research on macro-prudential policy, it is more from a macro perspective to consider the impact of macro-prudential policy on the whole macro-economy, financial system and financial sector. However, there are few studies from the perspective of micro-subject behavior. In particular [17], the impact of research policy tools on the ultimate goals of banks and other financial institutions is still relatively small. Even in the current few micro-perspective studies, the main data sources are based on the analysis of policy effectiveness based on bank or household credit.

\section{Double Pillar Policy and Risk Taking of Commercial Banks}

It is not difficult to find that adjusting interest rates for house prices or credit helps stabilize some of the economic variables, but also exacerbates the volatility of other variables, especially inflation. In contrast, the loan-to-income ratio is more suitable as the most effective tool to restrain excessive economic volatility; When an economic cycle is in a normal period, the economic driving force mainly comes from supply shocks, then the impact of macro-prudential policies on financial stability is relatively small; On the contrary, when an economic cycle is in an abnormal period, the economic driving force is mainly driven by financial shocks, then the impact of macro-prudential policies on financial stability will be more significant.

Monetary policy not only has a phased impact on the financial situation, but also has a long-term impact, which can effectively reduce financial instability in a long period of time. Macroprudential policy, by contrast, has a more imme- 
diate impact, but it comes and goes quickly. In the academic discussion in the past period, many scholars used the DSGE model tool to study the coordination mechanism of monetary policy and macro-prudential policy. The study found that the premise of monetary policy performing the function of economic management is that the economy is in a normal cycle, and when the economy is subject to financial shocks, the optimal policy combination of macro-prudential policy pegged to credit stability and monetary policy pegged to price stability should be adopted. In maintaining financial stability, macro-prudential policy can play a leading role, and play an auxiliary role in monetary policy, especially when financial shocks hit, this auxiliary effect is the most obvious; In terms of curbing household debt ratios, macro-prudential policy is more effective than monetary policy, and helps to reduce consumption volatility and improve social welfare. In the literature on the study of risk-taking channels, there is also a discussion on the interaction and coordination between policies. For example, when discussing whether the coordination of the two is complementary or alternative, it is proposed that the state of the economic system and the capital adequacy ratio of banks should be analyzed concretely. Some literatures have also noted the heterogeneity of bank risk-taking affected by monetary policy regulation. Under monetary easing conditions, those systemically important banks and those with a higher share of off-balance sheet business take higher risks, and respond to loose monetary policy more than other banks. Those with a higher share of their own capital and larger banks are more cautious; when banks expand their credit, they often take on more risks due to the encouragement of endogenous credit risk, which magnifies the pro-cyclical impact of credit. At this time, if they switch to monetary policy and macro-prudential policy to deal with the risk-taking, it helps to minimize the loss of benefits.

In the existing research on the macro-prudential regulatory framework and its coordinated use with monetary policy, we find that many of them are analyzed from the qualitative and quantitative perspectives, and the conclusions are very enlightening. As far as macro-prudential policy itself is concerned, it is often necessary to make requirements on the liquidity and leverage ratio of banks, which shows that reverse periodicity is its own natural attribute, and its ultimate goal is to guard against systemic financial risks and to stabilize the financial system. Because some indicators of commercial banks will be affected by the supervision of macro-prudential policy tools, they are often used as explanatory variables in some empirical studies on macro-prudential policies. It is used to analyze the effect of macro-prudential policy on commercial bank risk and credit growth.

This kind of literature is further subdivided into two kinds. One is to modify and adjust the core equation of DSGE model from the perspective of theoretical model, so as to endow it with macroprudential policy constraints or some related contents. In order to analyze the effectiveness and welfare effects of macro-prudential policies.

Wang Aijian and Wang Jianyi added counter-cyclical capital instruments to 
the DSGE model for simulation analysis, and reached a conclusion through parameter correction. It is considered that counter-cyclical macro-prudential policy and monetary policy have complementary effects in the field of financial stability and economic stability. The former can significantly increase welfare and reduce credit fluctuations caused by the latter. In some subsequent studies, macro-prudential policy has been developed on a larger scale, and more macro-prudential policy tools have been absorbed into the model. For example, in his research, Fang Yiji verified the correctness of China's macro-prudential policy practice. He used the GNSS model to confirm that China's macro-prudential policy is implemented by reasonably pegging the loan-to-value ratio of house prices, credit and output deposit-loan ratio. It not only helps to achieve the optimal monetary policy environment, but also continues to improve social well-being, and further concludes that only when the target is consistent with the regulatory object, the resulting macro-prudential policy is the most effective.

\section{Conclusions}

The impact of monetary policy on the risk-taking of commercial banks is mainly through the valuation effect, profit-seeking mechanism, commercial bank risk-taking channels, etc., which has an impact on the asset portfolio and risk-taking preference of commercial banks. The credit risk and liquidity risk of commercial banks are changed, so that the stability of the whole macro-finance is affected. As far as commercial banks are concerned, their business decisions will have a direct impact on the financing cost and financing difficulty of enterprises, and transmit this impact to the operating profits of enterprises until macroeconomic development. On the other hand, the macroeconomic operation will have an impact on the operating performance and risk-taking of commercial banks.

On the one hand, in China, the research on macro-prudential policy is mainly focused on the field of policy theoretical analysis of various countries, as well as the follow-up to the research progress of countries all over the world, even if the existing part of the research on the effectiveness of tools. It is also more focused on the micro level of banks. On the other hand, the empirical experience of China's macro-prudential policy at the present stage shows that most of the macro-prudential regulatory tools in China are scientific and effective, especially in the long-term practice, the differential deposit reserve ratio system implemented in our country for a long time. It has been proved that the practice of restricting house prices to control systemic risk, which has been commonly used in the past, is not only practical, but also effective, and it is one of the macro-prudential supervision tools used for a long time in our country. As for the factors that limit the role of macroprudential instruments, they are mainly affected by the heterogeneity of banks and regional economic development. Due to the vast land and abundant resources in China, the regional economic development still has the characteristics of imbalance and imbalance. The large-scale and strong banks 
and the banks in the eastern developed areas have obvious comparative advantages in giving full play to the effectiveness of the tools. But at the same time, some studies, such as Xu Kun, have put forward different viewpoints. They have turned their attention to 106 commercial banks across the country by using the method of empirical analysis of panel data. It is considered that whether it is the inhibitory effect of counter-cyclical capital buffers on excessive credit expansion, or the impact of regulatory pressure channels on commercial banks' capital buffers and credit expansion in the case of counter-cyclical capital buffers, it is not significant.

From a certain point of view, macro-prudence evolved from the extension of micro-prudence, which has its unique advantages as well as shortcomings. The advantage is that compared with monetary policy, monetary policy is more flexible, less time lag, and can be targeted at the risks of specific industries and loan portfolios. The disadvantage is that it is difficult to implement the goal of financial stability regulation and control. Therefore, the relationship between macro-prudential policy and other policies is gradually entering the scope of academic research. With regard to the relationship between macro-prudential policy and monetary policy, the mainstream view in all kinds of literature analysis is that they combine and strengthen each other. The principle contained in it has two aspects: on the one hand, the implementation of macro-prudential policy can help to improve the flexibility of the financial system, enhance the operating space of monetary policy, and promote the transmission of monetary policy, so as to achieve the goal of policy regulation and control; on the other hand, the implementation of monetary policy can reduce the pro-cyclical fragility of the financial system from channels such as asset prices, thus helping to achieve macro-prudential regulatory objectives. Most scholars believe that the two promote each other, in the face of general risk shocks, the two will not restrict each other, but in the face of non-traditional shocks, the two coordinate with each other, which is conducive to economic stability.

\section{Conflicts of Interest}

The authors declare no conflicts of interest regarding the publication of this paper.

\section{References}

[1] Borio, C. and Zhu, H.B. (2012) Capital Regulation, Risk-Taking and Monetary Policy: A Missing Link in the Transmission Mechanism. Journal of Financial Stability, 8, 236-251. https://doi.org/10.2139/ssrn.1334132

[2] Buch, C.M., Eickmeier, S. and Prieto, E. (2011) In Search for Yield? New Survey-Based Evidence on Bank Risk Taking.

[3] Zhang, Q., Qiao, Y.F. and Zhang, B. (2013) Does the Bank Risk-Taking Channel of China's Monetary Policy Exist. Financial Research, No. 8.

[4] Xu, M.D. and Chen, X.B. (2012) Monetary Environment, Capital Adequacy Ratio and Risk Taking of Commercial Banks. Financial Research, No. 7, 48-62. 
[5] Liu, S.F. and Li, C. (2014) Monetary Policy Regulation, Bank Risk Taking and Macro-Prudential Management: An Empirical Analysis Based on Dynamic Panel System GMM Model. Nankai Economic Research, No. 5.

[6] Suh, H. (2012) Macroprudential Policy: Its Effects and Relationship to Monetary Policy. FRB of Philaddphia Working Paper No. 12-28.

[7] Wang, A.J. and Wang, J.Y. (2014) A Study on the Effect of Macro-Prudential Policy and Its Relationship with Monetary Policy. Economic Research, No. 4.

[8] Fang, Y. (2016) A Study on the Effectiveness of Macro-Prudential Policy. World Economy.

[9] Tabak, B.M., Noronha, A.C. and Cajueiro, D. (2011) Bank Capital Buffers, Lending Growth and Economic Cycle: Empirical Evidence for Brazil. 2nd BIS CCA Conference on Monetary Policy, Financial Stability and the Business Cycle.

[10] Mora, N. and Logan, A. (2012) Shocks to Bank Capital: Evidence from UK Banks at Home and Away. Applied Economics, 44, 1103-1119. https://doi.org/10.1080/00036846.2010.537639

[11] Jarrow, R. (2013) A Leverage Ratio Rule for Capital Adequacy. Journal of Banking \& Finance, 37, 973-976. https://doi.org/10.1016/j.jbankfin.2012.10.009

[12] Cerutti, E., Claessens, S. and Laeven, L. (2017) The Use and Effectiveness of Macroprudential Policies: New Evidence. Journal of Financial Stability, 28, 203-224. https://doi.org/10.1016/j.jfs.2015.10.004

[13] Liang, Q., Li, M. and Bu, L. (2015) A Study on the Effectiveness of Macro-Prudential Policy Tools in China. Economic Science, No. 2, 5-16.

[14] Altunbas, Y., Gambacorta, L. and Marques-Ibanez, D. (2012) Do Bank Characteristics Influence the Effect of Monetary Policy on Bank Risk. Economics Letters, 117, 220-222. https://doi.org/10.1016/j.econlet.2012.04.106

[15] Delis, M.D. and Kouretas, G.P. (2011) Interest Rates and Bank Risk-Taking. Journal of Banking \& Finance, 35, 840-855. https://doi.org/10.1016/j.jbankfin.2010.09.032

[16] Özşuca, E.A. and Akbostancl, E. (2016) An Empirical Analysis of the Risk-Taking Channel of Monetary Policy in Turkey. Emerging Markets Finance and Trade, 52, 589-609. https://doi.org/10.1080/1540496X.2015.1047300

[17] Jiménez, G., Ongena, S., Peydró, J. and Saurina, J. (2012) Macroprudential Policy, Countercyclical Bank Capital Buffers and Credit Supply: Evidence from the Spanish Dynamic Provisioning Experiments. European Banking Center Discussion Paper, No. 11. https://doi.org/10.2139/ssrn.2049284 